\title{
Whole-body MR and cysticercosis
}

\section{Viroj Wiwanitkit}

Received: 27 January 2010 / Accepted: 12 February 2010

(C) Springer-Verlag 2010

\section{Sir,}

I read the report on cysticercosis by Kumar et al. [1] with great interest. Kumar et al. concluded that "Whole-body MR diagnosis of an infectious disease is unique" [1]. Indeed, whole-body MR diagnosis is useful for cysticercosis management, but it is not totally specific to this disease. There are also other cystic parasitic diseases in which wholebody MR diagnosis is useful and the finding of disseminated cysts can also be seen. The disseminated hydatid cyst is the best example [2,3]. This cystic disease should be an important differential diagnosis for cysticercosis.

\section{References}

1. Kumar A, Goenka AH, Choudhary A et al (2010) Disseminated cysticercosis in a child: whole-body MR diagnosis with the use of parallel imaging. Pediatr Radiol 40:223-227

2. Moharamzad Y, Kharazi HH, Shobeiri E et al (2008) Disseminated intraspinal hydatid disease. J Neurosurg Spine 8:490-493

3. Dziri C, Haouet K, Fingerhut A et al (2009) Management of cystic echinococcosis complications and dissemination: where is the evidence? World J Surg 33:1266-1273

\footnotetext{
V. Wiwanitkit $(\bowtie)$

Wiwanitkit House,

Bangkhae,

10160 Bangkok, Thailand

e-mail: wviroj@yahoo.com
} 